\title{
The Business Model of Health Websites
}

\author{
Tong Zhang a , Li Zhao \\ School of Information, Guizhou University of finance and economics, Guiyang 550025, China \\ a260234327@qq.com
}

Keywords: participants; business model; value creation; multilateral market.

\begin{abstract}
The discovery of business model about health websites has always been a hot topic in recent years. The main purpose of this article is to analyses the relationship among the main participants in health websites and clarify the value creations of them. In addition, we point out the business model of unilateral and multilateral market. At last, we present limitations of health website business model and summarize some suggestions of exploring business model.
\end{abstract}

\section{Introduction}

In recent years, Chinese government is actively promoting the development of medical informatization. People have always been enhancing the consciousness about health. With the development of health care market, a lot of health websites emerge in endlessly. The domestic health sites have met with many difficulties in the process of exploring business model. Therefore, how to combine the demands of the participants to keep balance and find various business model is the priority of medical health websites.

\section{Literature Review}

The interest around business model has increased among scholars and practitioners because of its valuable role. There are varying definitions of what a business model is, and these interpretations vary depending on their context and scope. For the purposes of this article, the most useful definition is that of Al-Debei et al.(2008) ${ }^{[1]}$, as follows: The business model is the design of transaction content, structure and governance so as to create value through the exploitation of business opportunities. Core products and services are included-these are part of the customer value proposition.

Several studies show that business model changes are among the most sustainable forms of innovation (Sosna et al., 2010) ${ }^{[2]}$. Business model innovation has been studied from different perspectives: sources of business model innovation, from performance, corporate transformation, barriers to innovation, processes of innovation, and different types of innovation amongst others. Our literature review focuses on value creation of business model innovation. The customer value corresponds with the customer's willingness to pay for a product or service. Customer value added results if the product's perceived value exceeds its price. If the product's cost is below its price, the company generates a profit. In short, we should not ignore the role of value creation in a business model.

\section{Health Website Participants}

In the process of transaction, in order to ensure the normal operation of health websites, business model is very important. According to each part of the ecosystem in health websites, participants include consumers, pharmaceutical enterprises, medical institutions, insurance companies, government and supportive enterprises. Among them, every participant consists of multiple parts. For example, the consumer can be the general public, patients or doctors; Pharmaceutical companies may include medical suppliers and medical equipment suppliers; Medical institutions such as hospitals, clinics and emergency centers, are a variety of health institutions engaged in disease diagnosis and treatment. Government departments have the ministry of health, ministry of commerce and the food and drug administration, which plays an important role in supervision and management. Supportive 
enterprises have a wider range, including scientific research institutions and software developers or system integrators. In the diagram, each participation constitutes the ecosystem of health website.

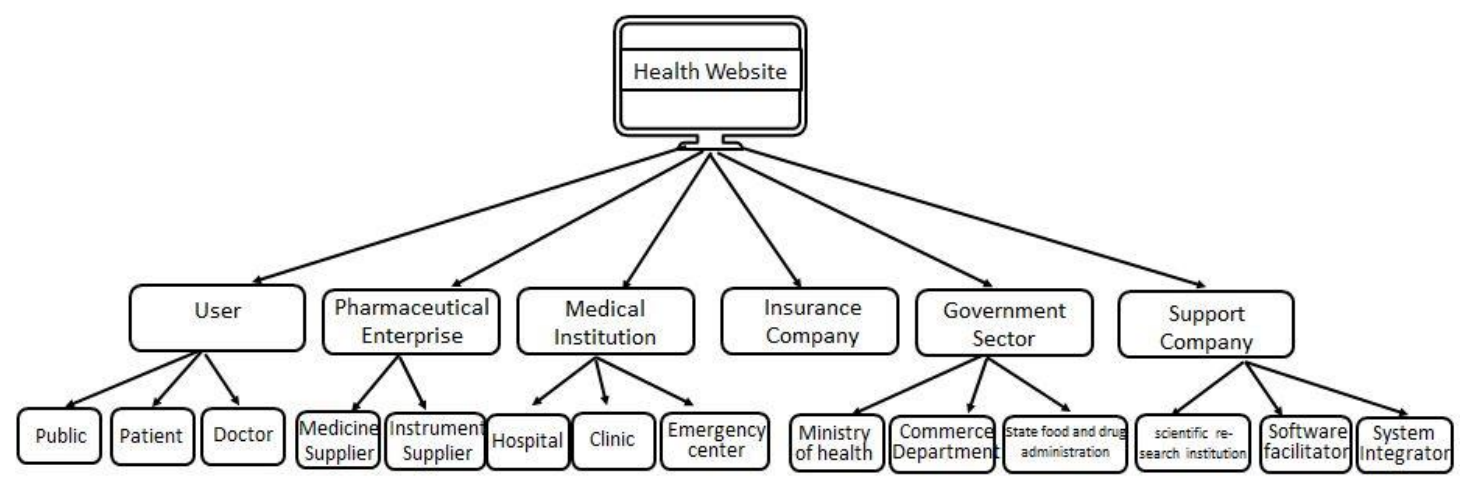

Fig. 1 health website participants

In the short term, insurance companies and pharmaceutical companies have the strongest willingness to pay. The demand of Hospital and government is also obvious, but now it is more conservative. Consumers are still more willingly to pay for tangible products.

\section{Value creation among health website participants}

The value creation among participants in health websites is to emphasize the respect to customers and establish a consumer-experience oriented service mode. In order to have a symbiotic environment, the core strategy is organizing the health ecological system and integrating technical resources ${ }^{[3]}$. Through the improvement of the medical products and services, we can create a healthy ecosystem completely. According to classification of health websites, medical services will be subdivided.

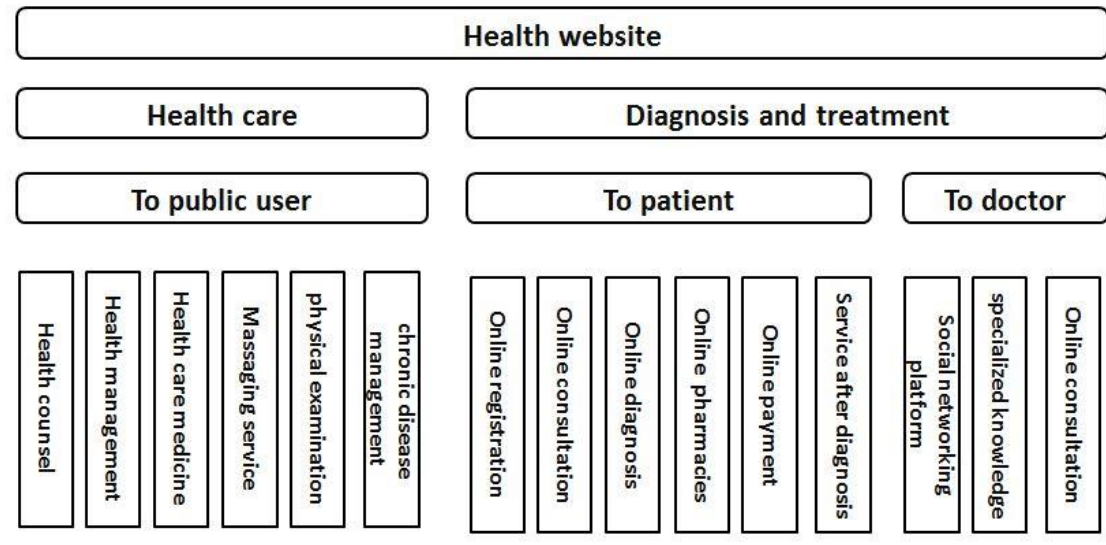

Fig. 2 medical service segment

\section{The business model of health websites among participants}

The business model of health websites are service-oriented business model, information business model, and trading business model ${ }^{[4]}$.

Service business model refers to using the Internet or mobile Internet (public or doctor) for the user to provide convenient medical services and charge the user mode for value-added fee.

Information business model refers to setting up advertisement on health consulting website, and it can also help users provide health advice and charge mode.

Transactional business model is using the Internet or mobile Internet to provide online trading platform or online pharmacy drugs for users and enterprises, and get commission and sales income. It includes users and enterprise oriented online pharmacy. 


\subsection{The business model of unilateral market}

\subsubsection{User and health website}

The business model between users and health websites is service business model. Via the Internet, it can provide convenient medical service to users (including the general public, patients and doctors), which charge users added money to achieve profitability ${ }^{[5]}$.

Medical services mainly include making an appointment, inquiring online and paying online. For instance, Appointments online payment can be paid according to times, or paid a monthly fee and a yearly fee. User's special value-added income is mainly composed of doctors and distribution platform, but doctors occupy larger initiative, which usually divide into rate from $70 \%$ to $90 \%$.

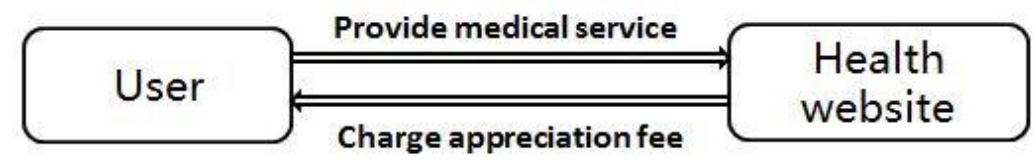

Fig. 3 user and website

\subsubsection{Pharmaceutical company and health website}

The business model between pharmaceutical companies and health websites is information business model. Health website pages will provide a lot of advertisement. In order to achieve the effect of drainage, pharmaceutical enterprises can promote the products of the company or online advertisement. In general, such ads payment are paid according to per click or the show time. Advertising costs vary from different locations. The current business model is to charge advertisement fee.

\begin{tabular}{|c|c|c|}
\hline \multirow{2}{*}{$\begin{array}{c}\text { pharmaceutical } \\
\text { enterprise }\end{array}$} & Release advertisement & Health \\
\hline & Charge advertiseme & W \\
\hline
\end{tabular}

Fig. 4 Pharmaceutical enterprise and health website

\subsection{The business model of multilateral market}

\subsubsection{Users, health websites and pharmaceutical companies}

The business model among users, health websites and pharmaceutical enterprises is trading business model. On the one hand, pharmaceutical companies can provide products for health websites, on the other hand, it also increase product sales channels. Users in health websites buy products such as medicines, medical apparatus and instruments. As a result, health websites from both sides can get profit.

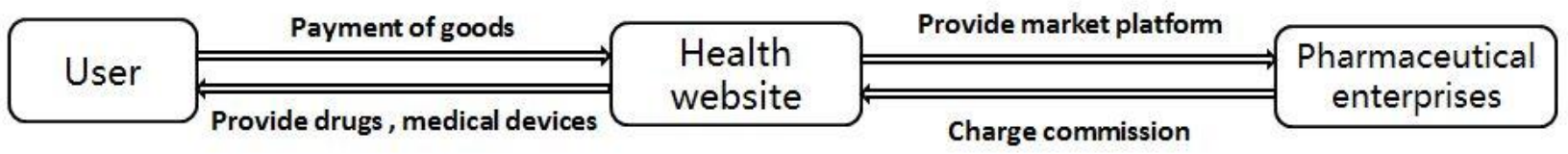

Fig. 5 Users, health website and pharmaceutical enterprise

\subsubsection{User, health website and insurance company}

Users, health website and Insurance Company's business model is same as users, health websites and pharmaceutical enterprise's business model. Both of them belong to the trading business model. The only difference is that, for insurance companies, they provide insurance business, and for pharmaceutical companies they provide medicines, medical equipment and other products. Currently Guahao.com has used this kind of business model, through the depth of the relevant institutions cooperation with mobile medical industry chain, creating with medicine, medicine and risk as the core of new business model and industry ecosystem.

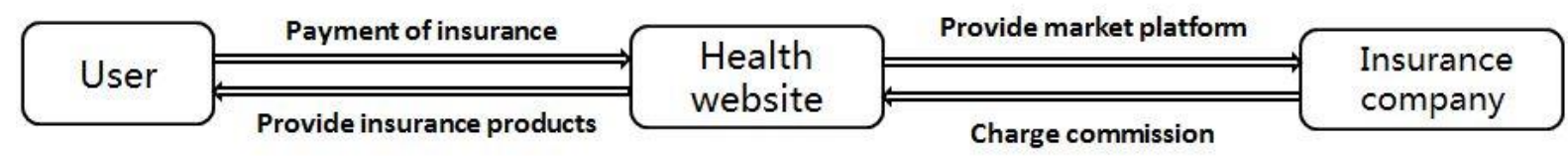

Fig. 6 User, health website and insurance company 


\section{The limitations of health website business model}

\subsection{The development stage of Internet}

With the high-speed development of Internet, the usage of it can partly be solved, but it is not fundamental. For example, people through Internet can make an appointment. However, there are quite a lot of old people who can't work on the Internet. At the same time, most online health care is also with a nature of consulting, returning feedback after a period of time. But in general, patients must be checked by doctors in person. To build trust between doctors and patients, it is hard to build trust online without face-to-face communication. Due to high medical industry requirement for precision and timeliness, current development stage of the Internet may hinder business model.

\subsection{The current health care system}

The current "medicine for the medical health system in China is the main reason that lead to high cost and difficulties in health care. "Medicine for the medical health system" refers to the last century, in order to maintain public hospital development and control the medical service cost, the government allows hospitals to add drug price than sold to patients. Some drug companies provide commission to some doctors to increase sales, and doctors prescribe more medicines to increase income ${ }^{[6]}$. Now, Health system in China lacks of effective control mechanism.

\subsection{The current situation of medical market}

Main participants in the healthcare industry are hospitals, doctors, and users. These parties have different disadvantages. First of all, top three hospitals have more patients, they are in a state of overload operation. However, general hospitals lack good doctor resources, with the medical resources waste and efficiency low. Secondly, doctors with lower qualification are under workload but have fewer income; Doctors with higher qualification are unable to satisfy intractable diseases patients. At last, due to unreasonable allocation of health resources in our country, both eastern and western regions, rural and urban areas, there is a big gap in less developed areas to see the doctor.

\subsection{Consumer's trust to the website}

In the current medical environment, although the Internet can make consumers enjoy the medical treatment of products and services online, public awareness is still not fully converted. Because of people's mistrust to the medical treatment website, they tend to pay more attention to "ill treatment". People often spend money on drugs rather than pay for online, which suggests that their awareness of "prevention" and "disease care" is not very high. The management of general public and patients are not mature enough, leading to the gap of the health management industry developed countries such as Europe and the United States. The business pattern of health websites is too difficult to explore.

\section{Suggestions and future research direction}

According to the limitation of health website business model, following suggestions should be put forward:

Specific consumer demand and develop core advantage. Medical products and services in the future will tend to be more personalized and customized, providing consumers with more accurate health information and increasing the consumer's satisfaction and trust.

Form a complete set of policies and establish relevant regulatory authorities. For example, for the laws and regulations of government departments, health and family planning branch network into such as regulators, providing medical service platform of Internet monitor.

Improve the medical service management business, to encourage health service innovation. Health websites should be according to the construction of residents' health records as an opportunity to establish a national residents health data sharing data center; On this basis, to encourage all kinds of third-party Internet medical service platform, value-added service platform of medical institutions in health management service innovation.

We believe that the suggestions provide a contribution to the business model innovation literature. However, we consider that it is necessary to conduct further research. The relationship among participants are simple. It is essential to make it more complete. We hope to have contributed to its advancement and, more important, stimulated further research. 


\section{Acknowledgements}

Fund program: This article is the the phased objectives of 《business model innovation research of health website in big data era (Grant No. [2015]2022-2)》, which is supported by soft science project of science and technology office in Guizhou. IT is also the phased objectives of 《talent introduction program in Guizhou University of finance and economics》.

\section{References}

[1] Aldebei M M, Elhaddadeh R, Avison D. Defining the Business Model in the New World of Digital Business[M]// Proceedings of the Americas Conference on Information Systems (AMCIS). 2008.

[2] Sosna M, Trevinyo-Rodríguez R N, Velamuri S R. Business Model Innovation through Trialand-Error Learning: The Naturhouse Case [J]. Long Range Planning, 2010, 43(2-3): 383-407.

[3] Hilda B. Health literacy and patient information: developing the methodology for a national evidence-based health website.[J]. Patient Education \& Counseling, 2008, 73(3):551-6.

[4] Maříková P. Value Creation in E-business [J]. český finanční a účetní časopis, 2009, 2009(1): 7782.

[5] Yun J J, Yang J, Park K. Open Innovation to Business Model: New Perspective to connect between technology and market [J]. 2016.

[6] Ryan Neill Stott, Merlin Stone, Jane Fae. Business models in the business-to-business and business-to-consumer worlds - what can each world learn from the other?[J]. 2016, 31(8): 943954. 